\title{
Kounis syndrome - Report of 4 cases
}

\author{
Síndrome de Kounis - Relato de 4 casos \\ Catarina Coutinho', Marta Neto', Manuel Branco-Ferreira ${ }^{1,2}$, \\ Leonor Viegas $^{3}$, Manuel Pereira-Barbosa ${ }^{1}$
}

\section{ABSTRACT}

Kounis syndrome is described as the occurrence of myocardial injury following a hypersensitivity reaction triggered by allergen exposure. The actual incidence is unknown, as most of the information comes from case reports and there are no international recommendations. Kounis syndrome does not seem to be rare but rather underdiagnosed. We report and discuss the clinical presentation and management of 4 cases of Kounis syndrome. All patients presented with anaphylaxis and chest pain. Patient age ranged from 44 to 83 years. Anaphylaxis triggers were nonsteroidal anti-inflammatory drugs and antibiotics. It is important to recognize Kounis syndrome in order to conduct an adequate investigation and prevent further events. A major difficulty is that the treatment of the 2 entities (hypersensitivity reaction and acute coronary syndrome) may worsen each other. Large prospective studies are needed to establish definitive treatment guidelines for these patients.

Keywords: Kounis syndrome, acute coronary syndrome, anaphylaxis, allergy.

\section{Introduction}

Kounis syndrome (KS), described in 1991 by Kounis and Zafras, is characterized by the concurrence of acute coronary syndrome and allergic reaction. ${ }^{1}$ Although it can occur at any age, the most commonly affected age group is $40-70$ years $(68 \%){ }^{2}$

\section{RESUMO}

A síndrome de Kounis caracteriza-se pela ocorrência de uma síndrome coronária aguda no contexto de uma reação alérgica concomitante desencadeada por exposição a um alergênio. A sua incidência real é desconhecida e não há consenso relativamente à abordagem, uma vez que a maioria dos dados provem de relatos de casos. A síndrome de Kounis não parece ser uma entidade rara, mas é infrequentemente diagnosticada. Apresentamos quatro casos, a sua apresentação clínica e abordagem diagnóstica e terapêutica. Todos os doentes, com idades entre os 44 e os 83 anos, se apresentaram com anafilaxia e dor torácica. Os fatores desencadeantes foram fármacos: anti-inflamatórios não esteroides e antibióticos. Torna-se importante reconhecer a síndrome de Kounis, de modo a que possa ser feita investigação adequada e prevenidos novos eventos. A grande dificuldade reside no fato de que o tratamento das duas entidades (Reação de hipersensibilidade e Síndrome coronária aguda), pode agravar uma à outra. São necessários estudos prospetivos alargados de modo a estabelecer diretrizes definitivas para o tratamento destes doentes.

Descritores: Síndrome de Kounis, síndrome coronária aguda, anafilaxia, alergia.

$\mathrm{KS}$ is frequently misdiagnosed, sometimes leading to inadequate treatment. It results from coronary vasospasm or atheromatous plaque rupture, induced by mast cell release of histamine and inflammatory mediators during an allergic reaction. ${ }^{3}$

1. Serviço de Imunoalergologia, Hospital Santa Maria, Centro Hospitalar Universitário Lisboa Norte, Lisboa, Portugal.

2. Clínica Universitária de Imunoalergologia, Faculdade de Medicina, Universidade de Lisboa, Lisboa, Portugal.

3. Unidade de Imunoalergologia, Hospital Lusíadas de Lisboa, Lisboa, Portugal. 
Coronary angiography can confirm the absence of coronary artery disease (type I KS), the presence of preexisting coronary disease (type II KS), or stent thrombosis (type III KS). ${ }^{4} \mathrm{KS}$ can be triggered by numerous agents, such as drugs and environmental factors (eg, food and insect sting). Therapeutic management consists in treating the allergic reaction and reestablishing myocardial perfusion. Antihistamines and steroids can be used despite their potential effect on delaying myocardial healing. Epinephrine should be used in the presence of anaphylaxis, but its potential to worsen myocardial ischemia and to induce arrhythmias must be considered. 5

We report 4 cases of KS managed in our Immunoallergology Department.

\section{Case 1}

A 44-year-old man, with childhood asthma and without known cardiovascular risk factors, presented to the emergency department (ED) with the complaint of palmar itching and chest tightness 8 days after starting metamizole and acetaminophen (every 8 hours) in the postoperative period of inguinal hernia surgery. Baseline electrocardiogram (ECG) was normal, and no blood tests were ordered. His symptoms improved with intravenous steroids. $\mathrm{He}$ was discharged with an oral $\mathrm{H} 1$ antihistamine and referred to our Immunoallergology Outpatient Clinic. The patient reported that, 10 years earlier, he developed generalized itching 1 hour after intramuscular administration of diclofenac, which resolved spontaneously after 5 days. After this episode, he took acetaminophen with good tolerance on several occasions.

Skin prick tests with metamizole and acetaminophen were negative. In our Day Hospital, an oral provocation test with nimesulide was negative, but the oral provocation test with metamizole was positive, with generalized itching (mainly palmoplantar) and chest pain appearing immediately after the first dose (115 $\mathrm{mg}$ ). The patient also developed generalized erythema, without skin lesions. He was hemodynamically stable, with normal cardiopulmonary auscultation. ECG showed left bundle branch block (LBBB) with ST elevation in leads V1-V2; without troponinemia $(<0.02$ $\mathrm{ng} / \mathrm{L})$. He was treated with epinephrine $(0.5 \mathrm{mg} \mathrm{IM})$, clemastine (2 mg IV), hydrocortisone (200 mg IV), clopidogrel (300 mg PO), and enoxaparin (60 mg SC) and admitted to the hospital. An echocardiogram showed apical hypokinesia of the inferior and inferior-septal wall. Coronary angiography showed eccentric plaque in the anterior descending artery and conditioning coronary artery stenosis of less than $30 \%$. The ECG was normal after 48 hours, and the echocardiogram was normal after 1 month.

Based on the confirmation of coronary artery stenosis, we made the diagnosis of type II KS due to metamizole.

\section{Case 2}

A 55-year-old woman, without known cardiovascular risk factors or allergic disease, developed generalized itching and erythematous maculopapular lesions, eyelid and upper lip edema, difficulty breathing, and chest pain 2 hours after taking oral diclofenac $(75 \mathrm{mg})$. Subsequently, she had 2 episodes of lipothymia with momentary loss of consciousness and was brought to the ED. Prior to this episode, she tolerated several nonsteroidal anti-inflammatory drugs (NSAIDs) well, such as acetaminophen, ibuprofen, and metamizole.

Forty-five minutes after the onset of symptoms, physical examination showed that she was hypotensive (blood pressure [BP] 70/30 mm Hg), eupneic, with face, eyelid, upper-lip, and tongue edema, upper limb erythema and wheezing. She was treated with clemastine (2 mg IV), hydrocortisone (200 mg IV), ranitidine (50 mg IV), and epinephrine (0.5 mg IM). As her BP did not respond, she received additional hydrocortisone (200 mg IV), methylprednisolone (80 $\mathrm{mg}$ IV), and a second dose of epinephrine $(0.5 \mathrm{mg}$ IM). There was a slow recovery of BP and regression of skin and respiratory symptoms. Ear, nose, and throat (ENT) examination confirmed no upper airway compromise. ECG was normal (Figure 1), but she had increased troponin levels (from 11 to $131 \mathrm{ng} / \mathrm{L}$ ). She was admitted to the hospital for monitoring, with no need for cardiac medication. She was discharged 5 days after admission, with normal troponin levels (15 ng/L).

Although coronary angiography was not performed, because the patient had no previous cardiac history, no cardiovascular risk factors and presented with a normal ECG, the diagnosis was type I KS due to diclofenac.

\section{Case 3}

A 55-year-old woman, with a history of hypertension, obesity, dyslipidemia, ischemic heart disease, and 
acute myocardial infarction and without known allergic disease, who was on long-term antiplatelet aggregation therapy with clopidogrel and acetylsalicylic acid (ASA), presented with chest pain with dyspnea, palmar itching, abdominal pain, and vomiting 2 hours after the first administration of amoxicillin/clavulanic acid $(875 / 125 \mathrm{mg})$ prescribed for respiratory tract infection. It was the first allergic episode with beta-lactams, which she had tolerated well previously.
On physical examination, she had upper and lower lip edema, generalized macular exanthema, and wheezing. ECG showed no signs of ischemia (Figure 2). She was treated with epinephrine (0.5 mg IM), clemastine (2 mg IV), and hydrocortisone (200 mg IV), with rapid improvement of the chest pain and palmar itching. On arrival at the ED, she was hemodynamically stable, but the wheezing, generalized exanthema, and abdominal pain were still present. The upper and

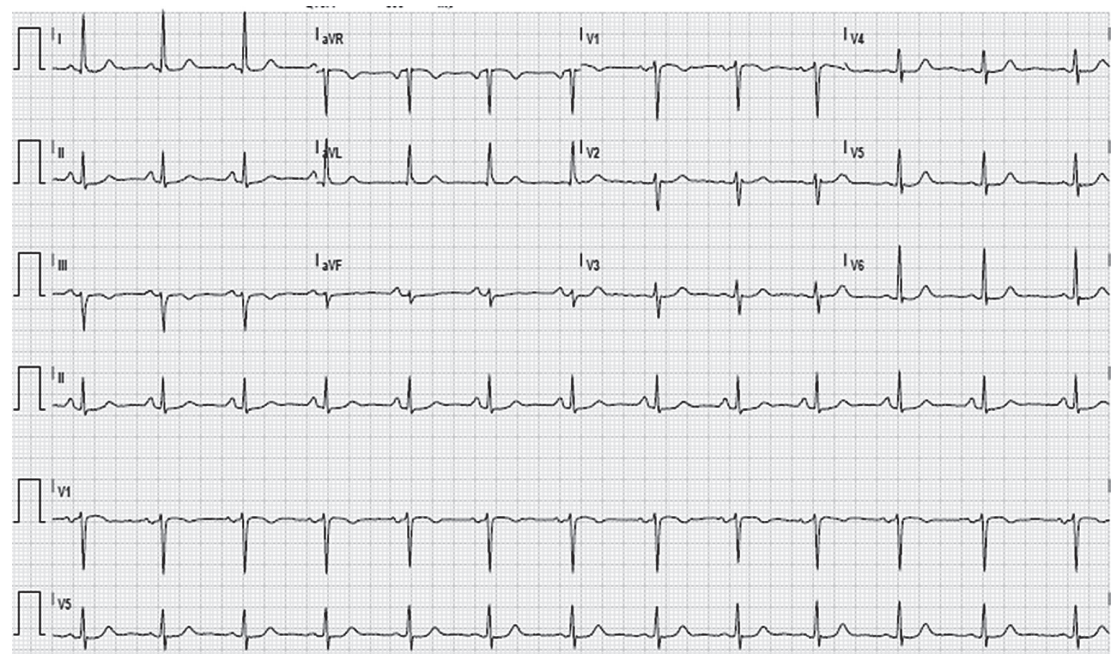

Figure 1

Patient 2's ECG: no signs of ischemia

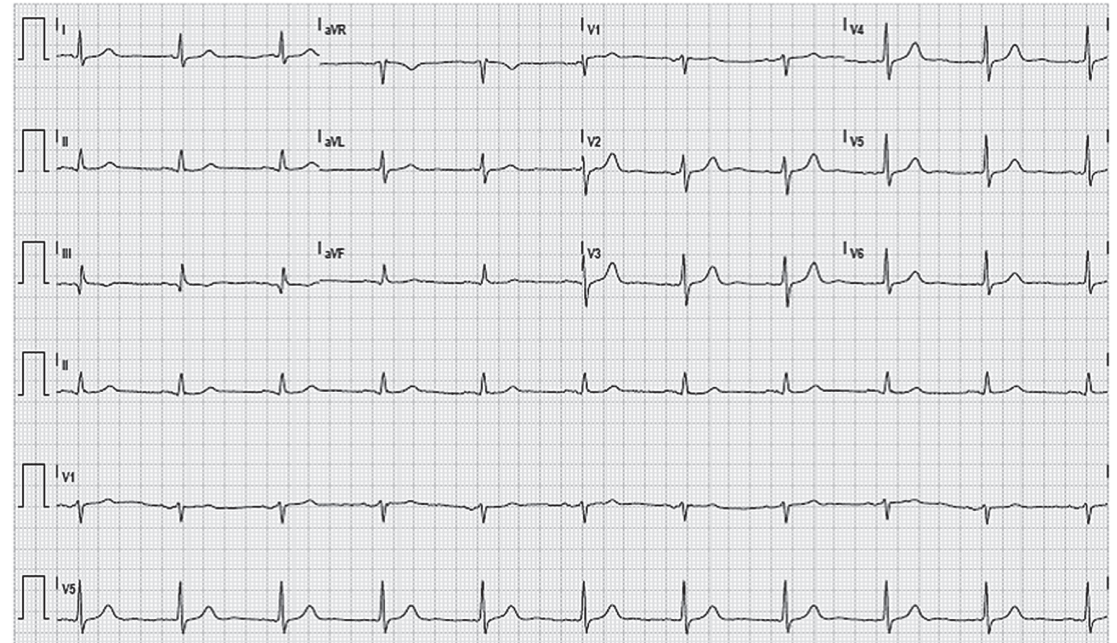

Figure 2

Patient 3's ECG: no signs of ischemia 
lower lip edema was slightly improved. Laboratory tests showed leukocytosis (17030/L) with neutrophilia (86.4\%) and C-reactive protein of $3.0 \mathrm{mg} / \mathrm{dL}$, with normal troponin levels $(<0.02 \mathrm{ng} / \mathrm{L})$. The patient was hospitalized for 3 days, with no further episodes of chest pain.

Although coronary angiography was not performed, because the patient had previous ischemic heart disease and several cardiovascular risk factors, the diagnosis was type II KS due to amoxicillin/clavulanic acid.

\section{Case 4}

An 83-year-old woman with a history of hypertension, heart failure, dyslipidemia, and primary hyperparathyroidism and without known allergic disease, who was on long-term antiplatelet aggregation therapy with ASA, was admitted to a hospital for the treatment of lower limb venous ulcer, for which she was prescribed intramuscular gentamicin. Apparently, it was the first time that she took this antibiotic, as she could not provide any information regarding previous antibiotic prescriptions. Ten minutes after administration, she developed generalized urticaria and thoracalgia, with loss of consciousness for a few seconds and hypotension (BP 70/50 mm Hg). Epinephrine (0.5 mg IM) was promptly administered, but she remained hypotensive.
Two additional epinephrine injections were required to normalize BP. Baseline ECG was performed in the ambulance and showed ST-segment elevation in anterior leads, compatible with acute coronary syndrome (Figure 3).

On arrival at the ED, she was asymptomatic with BP $80 / 56 \mathrm{~mm} \mathrm{Hg}$, heart rate $74 \mathrm{bpm}$, peripheral oxygen saturation $100 \%$ (with supplemental oxygen $4 \mathrm{~L} / \mathrm{min}$ ), and normal cardiopulmonary auscultation. She was treated with methylprednisolone (80 mg IV), clemastine (2 mg IV), and ranitidine (50 mg IV).

Laboratory tests showed elevated troponin levels (632 ng/L). An echocardiogram showed akinesia of all mid-apical segments, with an apical ballooning pattern suggestive of Takotsubo syndrome. Emergent coronary angiography showed no coronary lesions, only akinesia of mid-apical segments and the apical ballooning pattern suggestive of Takotsubo syndrome.

She was admitted to the hospital and treated with prednisolone (25 mg IV) every 8 hours, loratadine (10 mg PO) every 12 hours, and enoxaparin (40 mg $\mathrm{SC}$, initial dose). The troponin levels decreased progressively (from 632 to 467 then to $169 \mathrm{ng} / \mathrm{L}$ ), and the patient was discharged after 4 days. Her last ECG showed sinus rhythm, with frequent ventricular extrasystoles, left axis deviation, and incomplete de novo right bundle branch block (RBBB) (Figure 4).

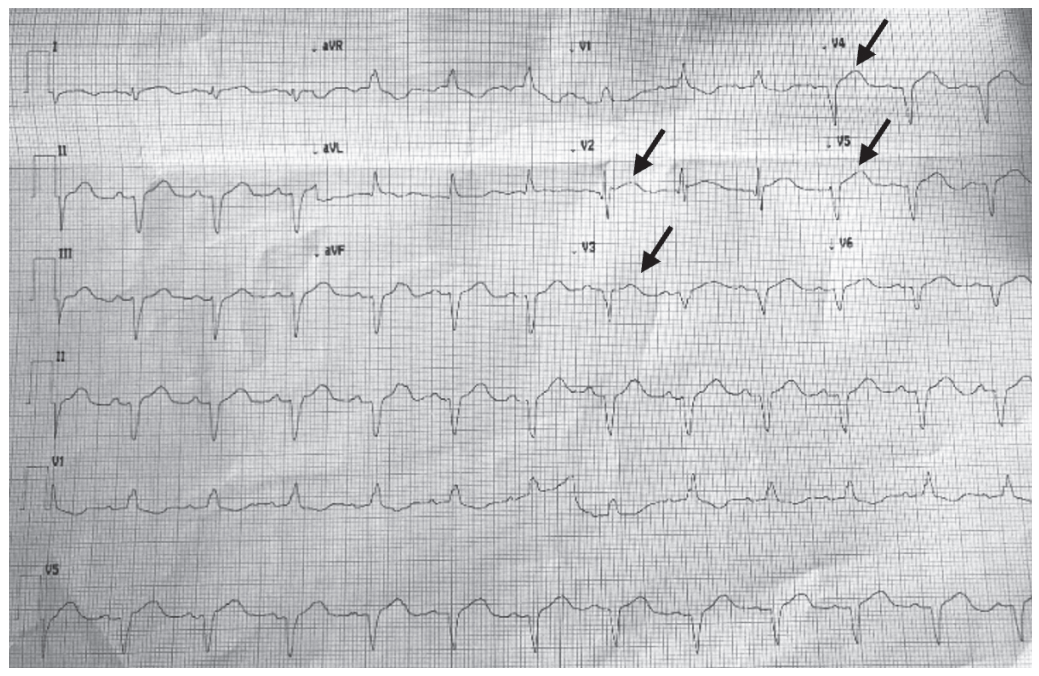

Figure 3

Patient 4's ECG: ST elevation in leads V2-V5 (arrows) 




Figure 4

Patient 4's ECG: Incomplete right bundle branch block (arrows)

Although ECG and echocardiogram showed abnormal findings, coronary angiography showed no coronary lesions, so the diagnosis was type I KS due to gentamicin.

Table 1 summarizes all 4 cases described here.

\section{Discussion}

$\mathrm{KS}$ is defined as the concurrence of acute coronary syndrome (coronary spasm, myocardial infarction, or stent thrombosis) and the activation of mast cells, platelets, and other inflammatory cells (eg,

Table 1

Summary of the 4 cases

\begin{tabular}{|c|c|c|c|c|}
\hline Patient & 1 & 2 & 3 & 4 \\
\hline Age, years & 44 & 55 & 55 & 83 \\
\hline Sex & $M$ & $\mathrm{~F}$ & $\mathrm{~F}$ & $\mathrm{~F}$ \\
\hline Cardiovascular risk factors & No & Yes & Yes & Yes \\
\hline Allergic disease & Childhood asthma & No & No & No \\
\hline Drug involved/suspected & Metamizole & Diclofenac & $\begin{array}{l}\text { Amoxicillin/ } \\
\text { clavulanate }\end{array}$ & Gentamicin \\
\hline ECG & $\begin{array}{l}\text { LBBB with ST elevation } \\
\text { in leads } \mathrm{V} 1-\mathrm{V} 2\end{array}$ & Normal & Normal & RBBB \\
\hline Troponin & Negative & $131 \mathrm{ng} / \mathrm{L}$ & Negative & $632 \mathrm{ng} / \mathrm{L}$ \\
\hline Coronary angiography & Coronary stenosis & Not performed & Not performed & No coronary lesions \\
\hline KS type & II & I & II & I \\
\hline
\end{tabular}

$\mathrm{M}=$ male, $\mathrm{F}=$ female, $\mathrm{ECG}=$ electrocardiogram, $\mathrm{LBBB}=$ left bundle branch block, RBBB = right bundle branch block, $\mathrm{KS}=\mathrm{Kounis}$ syndrome 
macrophages and T lymphocytes) in the context of an allergic reaction. ${ }^{3}$ Three types of KS have been described:

- Type I (no preexisting coronary disease): it presents with chest pain during a hypersensitivity reaction in patients without cardiovascular risk factors or coronary lesions. The allergic reaction induces coronary spasm, resulting in chest pain and/or ECG changes secondary to ischemia (however, sometimes the ECG can be normal, as in our patient 2). Cardiac enzymes may be either increased (as in our patients 2 and 4 ) or normal ${ }^{6}$ (as in our patients 1 and 3 );

- Type II (patients with coronary disease): it presents with chest pain during a hypersensitivity reaction in patients with preexisting coronary disease, such as atherosclerosis. It has been proposed that the release of inflammatory mediators induces plaque erosion or rupture, resulting in cardiac ischemia. ECG and cardiac enzymes may either be normal or show changes compatible with cardiac ischemia ${ }^{6}$;

- Type III (coronary stent thrombosis in the context of an allergic reaction): recurrent coronary events following drug-eluting stent placement may represent not only a local phenomenon but also a generalized hypersensitivity reaction, including the release of mediators capable of inducing thrombotic and/or vasoconstrictive phenomena. Cases of severe, diffuse spasm in several coronary arteries have been described after drug-eluting stent placement. ECG may show abnormalities due to ischemia, and cardiac enzymes may be increased. 4,7

It is important to note that, in the 3 types of KS, cardiac enzymes and/or ECG can be normal, ${ }^{3}$ as observed in some of our patients.

KS can be induced by several agents. Allergens induce mast cell degranulation, which leads to local and systemic secretion of vasoactive mediators (histamine, leukotrienes) with coronary vasoconstrictor effect and of proteases (tryptase) capable of activating metalloproteinases with collagen degradation and erosion of the atherosclerotic plaque, thus resulting in cardiac ischemia. ${ }^{6}$

KS is often underdiagnosed. ${ }^{3}$ The diagnosis is essentially clinical, but it may also be based on laboratory, ECG, and echocardiographic abnormalities or on abnormal coronary angiography (except for type I KS). Therefore, KS should be suspected in patients with allergic reactions concurrent with clinical, laboratory, or ECG abnormalities suggestive of cardiac ischemic injury. Clinical history is essential to establish a cause-effect relationship between allergen exposure and symptom onset; thus, it is also essential to adequately explore the patient's allergic history. ${ }^{3,4}$

Measuring tryptase and cardiac enzymes (troponin, CK-MB) may be useful in the diagnosis of anaphylaxis and acute coronary syndrome, respectively. Echocardiogram and coronary angiography can show absence/presence of cardiac wall-motion abnormalities and characterize normal/abnormal coronary arteries, thus allowing to diagnose type I or II/III KS. 3,4,6

There are no specific treatment guidelines, and the recommendations are based on cases reported in the literature. ${ }^{8}$ Both the allergic reaction and myocardial ischemia must be treated. Patients with type I KS may benefit from the treatment of the allergic reaction, which, by itself, may resolve the cardiac manifestations, ${ }^{2}$ as in our patients 2 and 4 . In patients with type II or III KS, in addition to treating the allergic reaction, the acute coronary event may be managed conservatively or invasively with angioplasty and percutaneous coronary intervention, ${ }^{9}$ as performed in our patient 1 . In our patient 3 , with a diagnosis of type II KS, there was a rapid improvement in chest pain after the allergic reaction was treated with epinephrine, antihistamines, and cortisone. Because the patient was on long-term antiplatelet aggregation therapy, no other specific treatment was given for acute myocardial ischemia.

$\mathrm{KS}$ is a severe allergic reaction in which epinephrine is the drug of choice to treat life-threatening symptoms of anaphylaxis. ${ }^{5}$ Nevertheless, treatment can be challenging, since the drugs used separately for each condition (allergic and cardiac) may be contraindicated for use in the same patient, as some drugs used to treat the acute coronary event may worsen the allergic reaction and vice-versa. ${ }^{5}$ For example, morphine, which is used to relieve acute thoracalgia, should be avoided because it can induce mast cell degranulation and histamine release, thus exacerbating the allergic reaction; $\beta$-blockers may reduce the action of epinephrine; nitrates may contribute to hypotension and tachycardia, although they are considered safe in the presence of hemodynamic stability; epinephrine may exacerbate coronary spasm and ischemia, as well as QT interval prolongation and arrhythmias; and steroids may delay myocardial healing. ${ }^{10}$ 
Regarding antiplatelet aggregation, required for the treatment of the acute cardiac event, the use of ASA is contraindicated in patients with a history of NSAID hypersensitivity. ASA is a powerful COX-1 inhibitor, so there is a risk of cross-reactivity with other NSAIDs. ${ }^{11}$ In our patients 1 and 2 , the causative agents were NSAIDs (metamizole and diclofenac, respectively); therefore, ASA was not administered. As an alternative, other antiplatelet agents, such as clopidogrel or ticlopidine, ${ }^{10}$ can be administered, as performed in our patient 1.

Overall, the prognosis of $\mathrm{KS}$ is good and complete patient recovery is expected, mainly because type $\mathrm{I}$ is the most common type of $\mathrm{KS}^{2}$ Nevertheless, in all cases of drug-induced KS, the prognosis depends on the magnitude of the initial allergic reaction, patient comorbidities, and allergen concentration and administration route. ${ }^{3}$

\section{Conclusion}

KS should be considered whenever dealing with patients with symptoms of acute coronary syndrome in the context of an anaphylactic reaction. Some patients may have cardiovascular risk factors or a history of cardiac disease, but others do not have any known or identifiable cardiac history. ECG and cardiac enzymes may show changes secondary to cardiac ischemia, but normal findings do not exclude the diagnosis of KS. An accurate diagnosis should be made as early as possible to promptly start adequate treatment. ${ }^{5}$ Although epinephrine may exacerbate ischemia, its administration should not be delayed, as it is the cornerstone of anaphylaxis treatment. If NSAID hypersensitivity is suspected, ASA should be avoided as an antiplatelet drug. Further studies are needed for a better understanding of the pathophysiological mechanism of KS in order to optimize therapeutic and preventive strategies.

\section{References}

1. Kounis N, Zavras G. Histamine-induced coronary artery spasm: the concept of allergic angina. Br J Clin Pr. 1991;45(2):121-8.

2. Abdelghany $M$, Subedi $R$, Shah $S$, Kozman $H$. Kounis syndrome: A review article on epidemiology, diagnostic findings, management and complications of allergic acute coronary syndrome. Int J Cardiol. 2017;232:1-4.

3. Kounis NG. Kounis syndrome: An update on epidemiology, pathogenesis, diagnosis and therapeutic management. Clin Chem Lab Med. 2016;54(10):1545-59.

4. Memon S, Chhabra L, Masrur S, Parker MW. Allergic acute coronary syndrome (Kounis syndrome). Proc (Bayl Univ Med Cent). 2015;28(3):358-62.

5. Omri M, Kraiem H, Mejri O, Naija M, Chebili N. Management of Kounis syndrome: Two case reports. J Med Case Rep. 2017;11(1):1-6.

6. Cepeda PR, Herrejón EP, Aguirregabiria MMR. Kounis syndrome. Med Intensiva. 2012;36(5):358-64.

7. Almeida J, Ferreira S, Malheiro J, Fonseca P, Caeiro D, Dias A, et al. Causa rara de síndrome coronária aguda: síndrome de Kounis. Rev Port Cardiol. 2016;35(12):10-3.

8. Marinheiro R, Amador P, Semedo F, Sá C, Duarte T, Gonçalves $S$, et al. Enfarte agudo do miocárdio intra-hospitalar: um caso de síndrome de Kounis tipo II. Rev Port Cardiol. 2017;36(5):10-4.

9. Dogan V, Özge G, Sungur F, Kadir U, Biteker M. Treatment of Kounis syndrome. Int J Cardiol. 2015;181:133-4.

10. Cevik C, Nugent K, Shome GP, Kounis NG. Treatment of Kounis syndrome. Int J Cardiol. 2010;143(3):223-6.

11. Kowalski ML, Asero R, Bavbek S, Blanca M, Blanca-Lopez N, Bochenek $G$, et al. Classification and practical approach to the diagnosis and management of hypersensitivity to nonsteroidal anti-inflammatory drugs. Allergy. 2013;68(10):1219-32.

No conflicts of interest declared concerning the publication of this article.

Corresponding author:

Catarina Coutinho

E-mail: catarinapc@ hotmail.com 